\title{
Tingkat Prokrastinasi Akademik Siswa Sekolah Menengah Pertama Muhammadiyah 9 Yogyakarta
}

\author{
Martika Laely Munawaroh, Said Alhadi, Wahyu Nanda Eka Saputra \\ Program Studi Bimbingan dan Konseling, Fakultas Keguruan dan Ilmu Pendidikan, \\ Universitas Ahmad Dahlan, Jl. Pramuka No. 42, Yogyakarta, Daerah Istimewa Yogyakarta, Indonesia 55161 \\ E-mail: wahyu.saputra@bk.uad.ac.id
}

Artikel diterima: 25 Januari 2017; direvisi 24 Februari 2017; disetujui 28 Februari 2017

\begin{abstract}
Academic procrastination is one of problems that may occur among junior high school students. This study aims to describe the level of academic procrastination of junior high school students in Sekolah Menengah Pertama Muhammadiyah 9 Yogyakarta. This research uses descriptive quantitative research. The results of this study showed that $17,2 \%$ of subjects have high academic procrastination, $77,1 \%$ of them have the moderate one, and $5,7 \%$ of them have the low one. Based on those results, it is recommended for the next researcher to use Solution-Focused Brief Counseling in reducing academic procrastination in SMP Muhammadiyah 9 Yogyakarta.
\end{abstract}

Keywords: academic procrastination; junior high school students; counseling

\begin{abstract}
Abstrak: Prokrastinasi akademik merupakan salah satu permasalahan yang terjadi di kalangan pelajar Sekolah Menengah Pertama (SMP). Penelitian ini bertujuan untuk mendeskripsikan tingkat prokrastinasi akademik siswa SMP Muhammadiyah 9 Yogyakarta. Penelitian ini menggunakan jenis penelitian deskriptif kuantitatif. Hasil penelitian menunjukkan bahwa $17,2 \%$ pelajar SMP Muhammadiyah 9 Yogyakarta memiliki prokrastinasi akademik tinggi, $77,1 \%$ sedang, dan 5,7\% rendah. Berdasarkan hasil penelitian tersebut, direkomendasikan agar peneliti selanjutnya menggunakan Konseling Ringkas Berfokus Solusi untuk mereduksi perilaku prokrastinasi akademik siswa SMP Muhammadiyah 9 Yogyakarta.
\end{abstract}

Kata kunci: prokrastinasi akademik; siswa sekolah menengah pertama; konseling

Dewasa ini, teknologi berkembang dengan sangat pesat. Perkembangan tersebut memiliki dampak positif dan negatif yang besar terhadap kehidupan manusia. Salah satu dampak negatif dimaksud adalah meningkatnya kecenderungan siswa menunda-nunda pekerjaan dengan melakukan kegiatan yang kurang bermanfaat di luar kegiatan akademik. Fenomena tersebut ditunjukkan dengan kebiasaan siswa yang menghabiskan waktu berjam-jam menonton televisi, mengakses jejaring sosial, bermain game online, dan mengakses situs-situs dewasa sebelum mereka belajar. Siswa lebih senang melakukan kegiatan-kegiatan di luar akademik yang kurang bermanfaat daripada mengerjakan tugas-tugas sekolah, mengulang pelajaran yang telah diberikan dan belajar untuk persiapan pelajaran esok hari.

Fenomena penundaan terhadap kegiatan yang seharusnya dikerjakan tepat waktu seperti disebutkan di atas dikenal dengan prokrastinasi. Menurut Knaus (2010) Procrastination berasal dari bahasa latin "pro" yang berarti mendorong maju atau bergerak maju dan akhiran "crastinus" yang berarti keputusan hari esok. Salah satu persamaan kata prokrastinasi ialah "cunctation" yakni menangguhkan atau menunda pekerjaan untuk dikerjakan di waktu yang lain. Knaus (2010) mendefinisikan prokrastinasi sebagai: "an automatic problem habit of putting off an important and 
timely activity until another time. It's a process that has probable consequences". Dalam konteks akademik, penundaan tersebut disebut sebagai prokrastinasi akademik. Prokrastinasi akademik sebagai penundaan terhadap tugas-tugas akademik seperti menulis makalah, mempersiapkan ujian, membaca untuk menyelesaikan tugas, melakukan administrasi terhadap tugas-tugas, kehadiran dalam kelas, dan menyelesaikan tugas akademik (Solomon \& Rothblum,1984). Terdapat beberapa penelitian tentang prokrastinasi akademik sudah pernah dilakukan sebelumnya. Sekitar $25 \%$ sampai 75\% pelajar memiliki masalah prokrastinasi akademik (Ferrari, Keane, Wolfe \& Beck, 1998). Penelitian di salah satu Sekolah Menengah Atas Kota Tangerang menunjukkan bahwa 43,70\% memiliki tingkat prokrastinasi tinggi dan 56,30\% lainnya memiliki prokrastinasi akademik rendah (Utaminingsih \& Setyabudi, 2012).

Prokrastinasi akademik yang dialami remaja jika tidak diidentifikasi dan berusaha diatasi akan berdampak negatif bagi siswa. Prokrastinasi berakibat pada banyaknya waktu yang terbuang sia-sia, tugas-tugas menjadi terbengkalai dan bila diselesaikan hasilnya menjadi tidak maksimal (Ferrari,1991). Prokrastinasi berkorelasi dengan rendahnya harga diri, depresi, pikiran-pikiran irasional, kecemasan, dan kurang percaya pada kemampuan diri (Solomon \& Rothblum, 1984). Prokrastinasi akademik juga berdampak negatif terhadap kegiatan akademik siswa. Siswa yang melakukan prokrastinasi akademik memiliki kecenderungan mendapat nilai rendah pada setiap mata pelajaran dan nilai ujian akhir (Steel, Brothen, \& Wambach, 2001) (Tice \& Baumeister (1997)).

Berdasarkan latar belakang di atas, penelitian ini bertujuan untuk memotret perilaku prokrastinasi akademik yang dialami oleh siswa Sekolah Menengah Pertama (SMP) Muhammadiyah 9 Yogyakarta. Hasil dari identifikasi diharapkan dapat menggambarkan tingkat prokrastinasi akademik siswa SMP Muhammadiyah 9 Yogyakarta sehingga dapat menjadi dasar untuk merancang penelitian lanjutan untuk menguji atau mengembangkan strategi konseling untuk mereduksi perilaku prokrastinasi akademik siswa SMP Muhammadiyah 9 Yogyakarta.

\section{METODE}

Penelitian ini menggunakan pendekatan deskriptif kuantitatif dengan tujuan untuk mendapatkan data aktual tentang tingkat prokrastinasi akademik siswa SMP Muhammadiyah 9 Yogyakarta. Subjek dalam penelitian ini adalah 35 siswa SMP Muhammadiyah 9 Yogyakarta. Para subjek diminta untuk mengisi Tuckman Procrastination Scale untuk mengukur tingkat prokrastinasi mereka yang akan diklasifikasikan menjadi tiga kategori: tinggi, sedang, dan rendah. Data hasil penelitian kemudian akan dianalisis dengan menggunakan teknik persentase.

\section{HASIL}

Berdasarkan hasil analisis, pelancaran Tuckman Procrastination Scale kepada 35 subjek memperoleh hasil: (1) sebanyak $17,2 \%$ subjek memiliki tingkat prokrastinasi akademik tinggi; (2) sebanyak 77,1\% subjek memiliki tingkat prokrastinasi akademik sedang; dan (3) sebanyak 5,7\% lainnya memiliki tingkat prokrastinasi akademik rendah. Secara visual, hasil tersebut ditampilkan dalam gambar 1 .

\section{PEMBAHASAN}

Temuan penelitian menunjukkan bahwa: (1) 17,2\% siswa SMP di Kota Yogyakarta memiliki tingkat prokrastinasi akademik tinggi; (2) 77,1\% memiliki tingkat prokrastinasi akademik sedang; (3) dan 5,7\% lainnya memiliki tingkat prokrastinasi akademik rendah. Temuan penelitian tersebut menunjukkan bahwa permasalahan prokrastinasi akademik masih dialami oleh siswa SMP Muhammadiyah 9 Yogyakarta. Tentunya hal ini perlu menjadi perhatian para guru, terutama konselor yang merupakan salah satu pihak yang bertanggungjawab untuk membantu siswa mengubah tingkah laku bermasalahnya. 


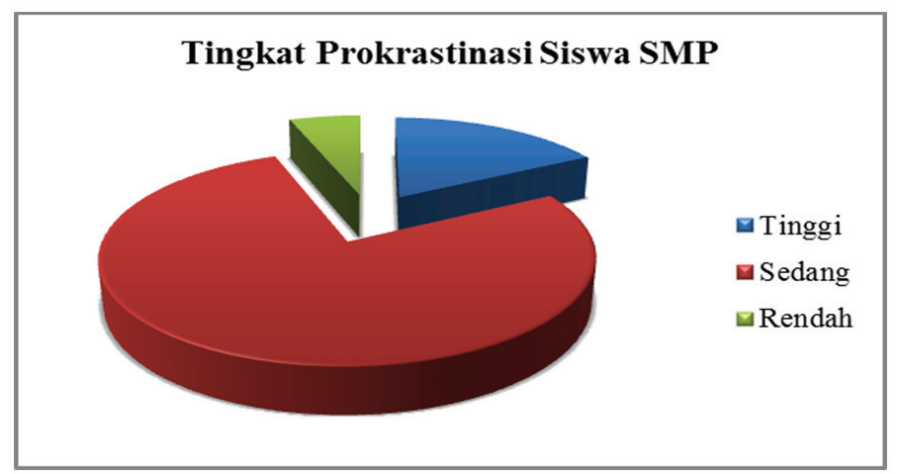

Gambar 1 Tingkat Prokrastinasi Akademik Siswa SMP Muhammadiyah 9 Yogyakarta

Temuan penelitian ini sejalan dengan penelitian terdahulu yang telah dilakukan oleh Ferrari, Keane, Wolfe \& Beck (1998). Penelitian tersebut menunjukkan sekitar 25\% sampai 75\% pelajar memiliki masalah prokrastinasi di lingkungan akademiknya. Penelitian ini juga sesuai dengan penelitian yang dilakukan oleh Utaminingsih \& Setyabudi (2012) di salah satu SMA Kota Tangerang, yang menunjukkan bahwa $43,70 \%$ subjek memiliki tingkat prokrastinasi tinggi dan 56,30\% sisanya memiliki prokrastinasi akademik rendah. Selain itu, Penelitian yang dilaksanakan oleh Saputra (2015) menunjukkan bahwa 7,1\% siswa menunjukkan prokrastinasi dalam bidang akademik kategori tinggi, $79,8 \%$ tergolong sedang, dan sisanya $13.1 \%$ tergolong rendah.

Prokrastinasi akademik yang dilakukan oleh siswa tidak terjadi dengan sendirinya tetapi disebabkan oleh berbagai faktor. Penyebab prokrastinasi siswa di lingkungan akademik karena faktor internal dan eksternal (Abu \& Saral, 2016). Faktor internal merupakan faktor yang berasal dari dalam diri siswa itu sendiri, seperti anggapan bahwa tugas adalah sesuatu yang tidak menarik, takut gagal, perfeksionisme, serta lebih memilih kegiatan yang lebih menyenangkan daripada mengerjakan tugas-tugas akademik. Adapun faktor eksternal merupakan faktor yang berasal dari luar diri siswa itu sendiri, seperti pendidikan guru yang kurang memadai, ajakan teman sebaya, dan kegiatan-kegiatan yang lebih menarik siswa untuk meninggalkan tugas-tugas akademiknya.

Berbagai faktor lain juga memiliki pengaruh terhadap prokrastinasi akademik siswa. Prokrastinasi siswa disebabkan oleh lima hal, yaitu: (1) waktu kehadiran di sekolah yang dianggap terlalu dini; (2) pola asuh orang tua; (3) pengaruh teman sebaya; (4) perfeksionisme; dan (5) memilih kegiatan yang lebih menyenangkan daripada mengerjakan kewajiban yang harus dikerjakan (Esmaeili \& Monadi, 2016). Motivasi siswa dalam belajar juga menentukan seorang siswa untuk melakukan prokrastinasi (Katz, Eilot \& Nevo, 2014).

Prokrastinasi akademik memiliki model paradigma yang mencakup anteseden prokrastinasi akademik, fenomena prokrastinasi itu sendiri, konteks dan kondisi, strategi coping, dan konsekuensi (Schraw, Wadkins \& Olafson, 2007). Model paradigma prokrastinasi akademik dimaksud diilustrasikan pada gambar 2. Pada gambar 2 dapat dijabarkan bahwa: pertama, antesenden prokrastinasi akademik. Peserta dikaitkan penundaan untuk tiga jenis anteseden, termasuk karakteristik diri, guru, dan tugas. Kedua, fenomena prokrastinasi itu sendiri. Prokrastinasi akademik sebenarnya bisa dilihat sebagai perilaku adaptif dan perilaku maladaptif. Disebut perilaku maladaptif karena prokrastinasi akademik berdampak negatif bagi pelakunya, sedangkan disebut adaptif karena individu menunda tugas karena mereka ingin mengerjakan tugas dengan lebih baik lagi. Ketiga, konteks dan kondisi. Terdapat tiga tema kontekstual yang memengaruhi penundaan, termasuk arah yang tidak jelas, tenggat waktu, dan kurangnya insentif. Guru sering tidak memberikan informasi yang cukup kepada siswa tentang isi dan struktur dari tugas. Keempat, strategi coping. Pada bagian ini berusaha untuk memunculkan sebuah strategi coping baik kognitif maupun afektif yang dapat digunakan konselor untuk bisa keluar dari masalah prokrastinasi akademik. Kelima, konsekuensi. Konsekuensi prokrastinasi akademik terdiri dari dua, yaitu keuntungan dan kerugian. Individu akan merasa memiliki keuntungan ketika melakukan prokrastinasi akademik karena mereka ingin 


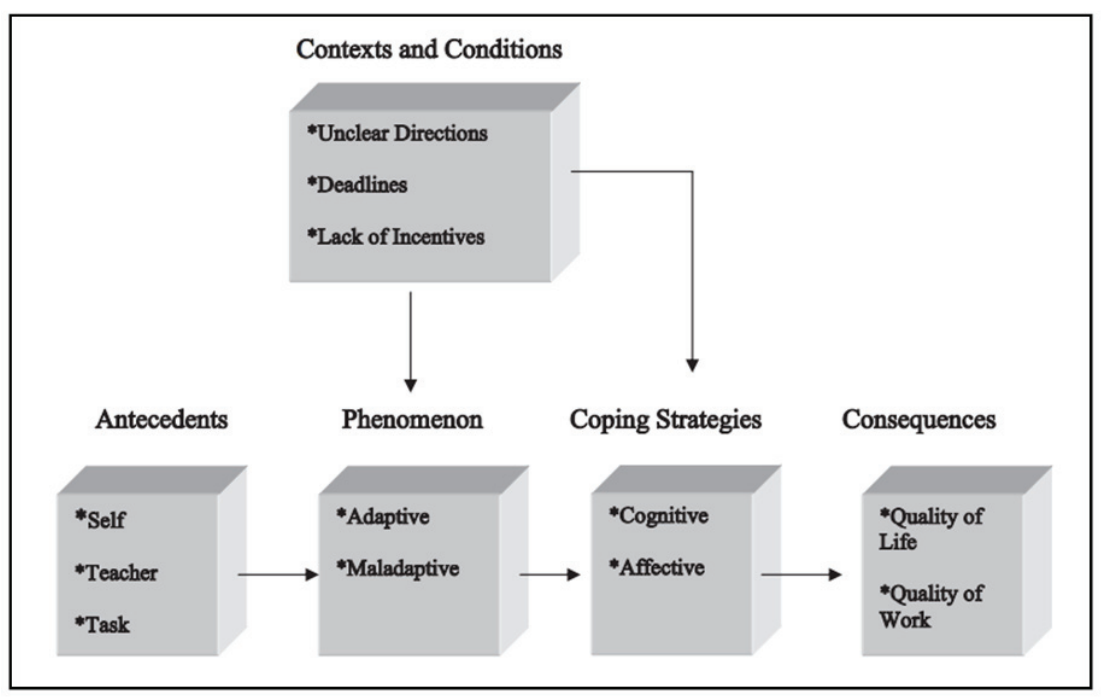

Sumber: Schraw, Wadkins \& Olafson (2007)

\section{Gambar 2 Model Paradigma Prokrastinasi Akademik}

mengerjakan tugas lebih baik lagi, sehingga memutuskan untuk menunda mengumpulkan tugas. Selain itu, individu akan merasa memiliki kerugian ketika mereka kehilangan kesempatan untuk mengembangkan pemahaman suatu topik dengan baik, perasaan kemalasan, dan kelelahan fisik.

Berdasarkan penjelasan di atas, prokrastinasi akademik yang dialami oleh siswa perlu diatasi karena prokrastinasi memiliki konsekuensi terhadap kesuksesan akademik siswa (De Paola \& Scoppa, 2015). Guru memiliki tanggung jawab besar untuk membantu siswa keluar dari permasalahan perilaku prokrastinasi (Xu, 2016), termasuk dalam hal ini adalah guru Bimbingan dan Konseling atau konselor. Konselor perlu merancang sebuah program yang secara khusus merespon permasalahan prokrastinasi siswa agar prokrastinasi yang mereka alami menurun.

Strategi untuk mereduksi prokrastinasi yang dialami siswa dapat dilakukan melalui tiga tingkatan, yaitu intervensi individual, klasikal, dan pencegahan dalam format kelas besar (Xu, 2013). Tingkatan pertama adalah intervensi individual yang dapat menerapkan intervensi konseling secara individual yang bertujuan untuk mereduksi prokrastinasi siswa. Tingkatan kedua adalah intervensi dalam format klasikal yang bertujuan untuk memberikan beragam strategi bagi siswa untuk menghindarkan diri dari perilaku prokrastinasi. Tingkatan ketiga adalah pencegahan dalam format kelas besar yang bertujuan untuk memberikan pemahaman pada siswa tentang bahaya dan dampak negatif prokrastinasi bagi siswa.

Berdasarkan tiga tingkatan di atas, salah satu strategi untuk mereduksi prokrastinasi akademik siswa adalah intervensi secara individual dengan menerapkan Konseling Ringkas Berfokus Solusi. Konseling Ringkas Berfokus Solusi memandang konseli memiliki masalah karena ketidakmampuannya dalam menemukan solusi bagi masalah yang dialaminya (Sommers-Flanagan \& Sommers-Flanagan, 2004). Konseling Ringkas Berfokus Solusi sesuai untuk setting sekolah karena dapat memunculkan perubahan pada diri konseli selama sesi konseling dengan waktu yang lebih singkat (Charlesworth \& Jackson, 2004).

Konseling Ringkas Berfokus Solusi memiliki asumsi yang menjadi pijakan konselor melakukan intervensi konseling. Salah satu asumsi dasar tentang Konseling Ringkas Berfokus Solusi adalah individu yang datang ke sesi konseling mampu berperilaku efektif meskipun perilaku yang efektif mungkin dihalangi sementara oleh pandangan negatif(Corey, 2009). Dengan dilaksanakan intervensi dengan Konseling Ringkas Berfokus Solusi, konselor dapat membantu konseli menghilangkan pandangan negatifnya sehingga konseli dapat merancang sebuah solusi untuk membantu mereka keluar dari masalah prokrastinasi akademiknya. 
Konseling Ringkas Berfokus Solusi dapat mereduksi perilaku negatif siswa seperti prokrastinasi akademik (Sklare, Sabella \& Petrosko, 2003). Pada penelitian tersebut berusaha menggabungkan antara Konseling Ringkas Berfokus Solusi dengan teknik guided imagery dan diterapkan tahap demi tahap untuk mereduksi prokrastinasi akademik yang dialami siswa. Rangkaian perlakuan yang dilakukan oleh konselor adalah berusaha untuk mendorong konseli untuk menutup mata dan membayangkan diri berpikir, merasa, dan berperilaku dalam cara-cara yang akan menunjukkan mereka dapat menyelesaikan masalah.

\section{SIMPULAN}

Berdasarkan penjabaran di atas dapat disimpulkan bahwa masalah prokrastinasi akademik masih dialami oleh siswa SMP Muhammadiyah 9 Yogyakarta. Temuan penelitian ini seyogyanya menjadi dasar bagi konselor untuk melakukan intervensi melalui konseling untuk mereduksi perilaku prokrastinasi akademik siswa. Salah satu pendekatan konseling yang bisa diterapkan konselor adalah Konseling Ringkas Berfokus Solusi. Dengan model konseling ini, konseli ditantang konselor untuk menghilangkan pandangan negatifnya untuk bisa keluar dari masalah prokrastinasi akademik sehingga konseli dapat merancang sebuah solusi untuk membantu mereka mereduksi perilaku prokrastinasi.

\section{DAFTAR RUJUKAN}

Abu, N. K., \& Saral, D. G. (2016). The Reasons of Academic Procrastination Tendencies of Education Faculty Students. The Online Journal of New Horizons in Education, 6(1), 165-169.

Corey, G. (2009). Theory and Practice of Counseling and Psychotherapy. Belmont, CA: Brook/ Cole.

Charlesworth, J. R., \& Jackson, C. M. (2004). Solution-Focused Brief Counseling: An Approach for Professional School Counselors. Dalam Erford, BT. Professional School Counseling: A Handbook of Theories, Programs and Practices. Austin, TX: Caps Press.

De Paola, M., \& Scoppa, V. (2015). Procrastination, Academic Success and The Effectiveness of A Remedial Program. Journal of Economic Behavior \& Organization, 115, 217-236.

Esmaeili, N., \& Monadi, M. (2016). Identifying the Causes of Academic Procrastination from the Perspective of Male Middle School Male Students. International Journal of Humanities and Cultural Studies (IJHCS), 2464-2487.

Ferrari, J. R. (1991). Self-handicapping by Procrastinators: Protecting Self-Esteem, Social-Esteem, or Both?. Journal of Research in Personality, 25(3), 245-261.

Ferrari, J. R., Keane, S. M., Wolfe, R. N., \& Beck, B. L. (1998). The antecedents and consequences of academic excuse-making: Examining individual differences in procrastination. Research in Higher Education, 39(2), 199-215.

Sommers-Flanagan, J., \& Sommers-Flanagan, R. (2004). Counseling and Psychotheraphy Theories in Context and Practice: Skills, Strategies and Techniques. New Jersey: John Wiley \& Sons, Inc.

Katz, I., Eilot, K., \& Nevo, N. (2014). "I'll do it later": Type of motivation, self-efficacy and homework procrastination. Motivation and Emotion, 38(1), 111-119.

Knaus, W. J. (2010). End Procrastination Now! Get It Done with a Proven Psychological Approach. New York: McGraw-Hill Companies, Inc.

Saputra, W. N. E. (2015). Perbandingan Prokrastinasi Akademik Siswa SMK melalui Penerapan Teknik Cognitive Restructuring dan Cognitive Defusion. (Tesis tidak diterbitkan). Universitas Negeri Malang, Malang, Indonesia.

Schraw, G., Wadkins, T., \& Olafson, L. (2007). Doing the Things We Do: A Grounded Theory of Academic Procrastination. Journal of Educational Psychology, 99(1) 12-25. 
Sklare, G. B., Sabella, R. A., \& Petrosko, J. M. (2003). A Preliminary Study of the Effects of Group Solution-Focused Guided Imagery on Recurring Individual Problems. Journal for Specialists in Group Work, 28(4) 370-381.

Solomon, L. J., \& Rothblum, E. D. (1984). Academic Procrastination: Frequency and CognitiveBehavioral Correlates. Journal of Counseling Psychology, 31(4) 503-509.

Steel, P., Brothen T., \& Wambach, C. (2001). Procrastination and Personality, Performance, and Mood. Personality and Individual Differences, 30(1) 95-106.

Tice, D. M., \& Baumeister, R. F. (1997). Longitudinal study of procrastination, performance, stress, and health: The costs and benefits of dawdling. Psychological Science, 8(6), 454-458.

Utaminingsih, S., \& Setyabudi, S. (2012). Tipe Kepribadian dan Prokrastinasi Akademik pada Siswa SMA "X" Tangerang. Jurnal Psikologi, 10(1) 48-57.

Xu, Z. (2016). Just Do It! Reducing Academic Procrastination of Secondary Students. Intervention in School and Clinic, 51(4), 212-219. 